\title{
Electron microscopy of Crotalaria pulmonary hypertension
}

\author{
J. M. KAY, PAUL SMITH, AND DONALD HEATH \\ From the Department of Pathology, University of Liverpool
}

\begin{abstract}
The lungs of 11 rats fed on Crotalaria spectabilis seeds for periods ranging from 12 to 61 days were examined by both light and electron microscopy. The findings were compared with those obtained from nine control rats given a normal diet. Eight of the 11 test rats showed morphological evidence of pulmonary arterial hypertension in the form of right ventricular hypertrophy ; the exceptions were rats killed after receiving the Crotalaria diet for 12,22 , and 29 days respectively. On light microscopy, all the test rats showed exudative lesions in the lungs consisting of eosinophilic alveolar coagulum, intra-alveolar haemorrhage, interstitial fibrosis, and a proliferation of mast cells. Enlarged and proliferated cells were seen to line the alveolar walls or lie free within the alveolar spaces. Electron microscopy showed these cells to be enlarged granular pneumocytes containing enlarged, electron-dense, lamellar secretory inclusions. Scanty macrophages were also seen in the alveolar spaces, in which excessive numbers of myelin figures and lattices were seen: these structures resembled phospholipid membranes and were probably related to pulmonary surfactant. We think that proliferation of granular pneumocytes is a non-specific reaction of the alveolar walls to injury. The alveolar-capillary wall showed interstitial oedema with the formation of intraluminal endothelial vesicles, probably representing the early ultrastructural phase of pulmonary oedema, and more likely to be an effect of the pulmonary hypertension than its cause.
\end{abstract}

One of the most interesting recent advances in the pathology of the pulmonary circulation has been the development of an experimental model for the study of pulmonary hypertension. This comprises the induction of an elevated pulmonary arterial pressure in rats by feeding them on Crotalaria spectabilis seeds (Kay, Harris, and Heath, 1967.b). The active constituent of the seeds is the pyrrolizidine alkaloid monocrotaline (Neal, Rusoff, and Ahmann, 1935), and its oral or systemic administration to rats induces pathological changes which are identical to those caused by ingestion of the seeds. These changes are cardiomegaly due to right ventricular hypertrophy (Turner and Lalich, 1965 ; Kay and Heath, 1966), thickening of the pulmonary trunk (Heath and Kay, 1967), medial hypertrophy of 'muscular pulmonary arteries' (Turner and Lalich, 1965 ; Kay and Heath, 1966), and, in a proportion of animals, an acute necrotizing pulmonary arteritis (Lalich and Merkow, 1961 ; Kay and Heath, 1966).

Histological examination of the lung parenchyma in treated rats reveals, in addition to the pulmonary vascular disease, a wide range of changes, including proliferation and desquamation of alveolar cells, pulmonary oedema, intra-alveolar haemorrhage, interstitial fibrosis, and a multiplication of mast cells. Such 'exudative lesions' may be the direct or indirect consequences of chronic exudation of blood or plasma constituents from the small pulmonary blood vessels into the alveolar walls and spaces (Kay, Gillund, and Heath, 1967a).

The purpose of the present investigation was to determine the ultrastructural changes which occurred in the alveolar walls and capillaries of rats given Crotalaria spectabilis seeds, to identify the nature of the proliferated and desquamated alveolar cells, and to relate these changes to the development of the pulmonary hypertension.

\section{METHODS}

Twenty female weanling Wistar albino rats weighing between 56 and $105 \mathrm{~g}$. were divided into a group of nine controls (C 1-9) and a group of 11 test animals (T 1-11). Both groups were fed on powdered rat cubes and water, but in the test rats the diet was adulterated with ground Crotalaria spectabilis seeds to give a final concentration of $0.1 \%$. From the twelfth day of the experiment test and control rats 
were killed with ether at intervals of about six days. Test rats $T 5$ and $T 7$ died spontaneously on the 33rd and 35 th days of the experiment, respectively. The lungs of all the remaining test rats and five of the control animals were studied by electron microscopy. Immediately after death small blocks of tissue (1 $\mathrm{mm}^{3}$ ) were cut from the right lung and fixed in ice-cold gluteraldehyde. The blocks of tissue were post-fixed in osmium tetroxide, stained with uranyl acetate, and embedded in araldite. Thin sections $(1 \mu)$ were cut with an LKB Ultratome III ultramicrotome, mounted on glass slides, and stained with toluidine blue for light microscopy and the selection of suitable areas for electron microscopy. The blocks were then trimmed and ultra-thin sections ( $900 \AA)$ were cut, stained with lead citrate, and examined in an AEI EM6B electron microscope.

In every case the thoracic viscera were removed in one block. The right bronchus was ligated, the trachea was cannulated, and the left lung was distended with buffered $10 \%$ formalin until its pleural surface was smooth: the organs were then immersed in a similar solution. When fixation was complete. the heart was dissected free and was opened. Blood and excess fixative were removed by blotting with fine gauze. The cardiac chambers were divided to obtain the weights of the free wall of the right ventricle, the left ventricle together with the inter-ventricular septum, and the two atria. The right ventricular weight was expressed as an inverse ratio of the weight of the left ventricle and interventricular septum (LV $+\mathrm{S} / \mathrm{RV}$ ) for assessment of right ventricular hypertrophy, the presence of which was accepted as morphological evidence of pulmonary hypertension. The use of this ratio excluded the influence of body weight in making comparisons of right ventricular weight.

A single block of tissue was taken from the left lung of each rat and embedded in paraffin wax for histological examination. Sections were cut at $5 \mu$ thickness and stained with haematoxylin and eosin, by Lawson's modification of the Weigert-Sheridan method for elastic fibres counterstained with Van Gieson's reagents for differentiating smooth muscle and collagen, by the Prussian blue method for ferric iron, and with $0 \cdot 2 \%$ metachromatic blue dissolved in $5 \%$ aqueous aluminium sulphate for the demonstration of mast cells.

\section{RESULTS}

RIGHT VENTRICULAR WEIGHT Figure 1 shows the relation between survival time and right ventricular weight, expressed as a ratio of the weight of

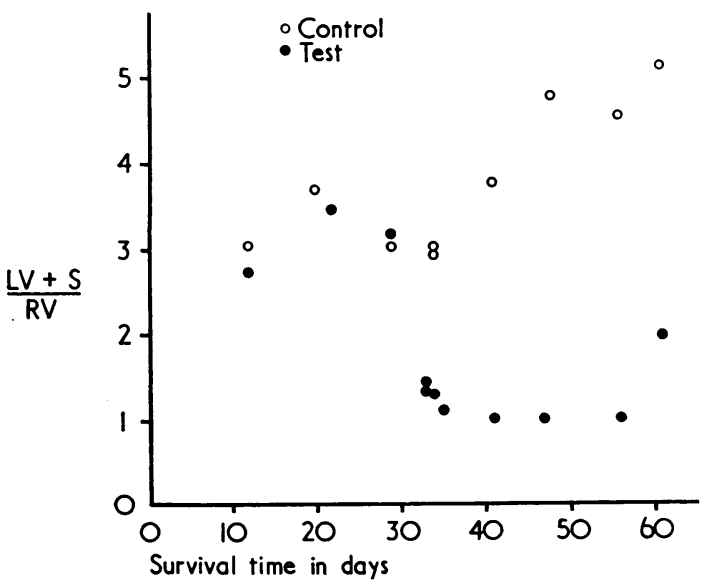

FIG. 1. Right ventricular weight $(R V)$ expressed as a ratio of the weight of the left ventricle and interventricular septum $(L V+S)$ in control rats and rats fed on Crotalaria spectabilis seeds.

the left ventricle and interventricular septum (LV $+\mathrm{S} / \mathrm{RV}$ ) in control and test rats. It demonstrates that in animals which died after 30 days there is a pronounced decrease of the $L V+S / R V$ ratio in test rats when compared with the controls. These data, which accord with those of previous experiments (Kay and Heath, 1966), indicate the development of right ventricular hypertrophy and pulmonary arterial hypertension in rats fed on Crotalaria spectabilis seeds.

T A B L E

EXUDATIVE LESIONS IN THE LUNGS OF RATS FED ON CROTALARIA SPECTABILIS SEEDS

\begin{tabular}{|c|c|c|c|c|c|c|c|c|c|}
\hline Rat & $\begin{array}{c}\text { Survival } \\
\text { (days) }\end{array}$ & HPVD & $\begin{array}{c}\text { Proliferated } \\
\text { Alveolar Cells }\end{array}$ & $\begin{array}{c}\text { Mast Cell } \\
\text { Proliferation }\end{array}$ & $\begin{array}{l}\text { Alveolar } \\
\text { Coagulum }\end{array}$ & \begin{tabular}{|} 
Pulmonary \\
Haemorrhage
\end{tabular} & $\begin{array}{l}\text { Sidero- } \\
\text { phages }\end{array}$ & $\begin{array}{c}\text { Dilated } \\
\text { Lymphatics }\end{array}$ & $\begin{array}{c}\text { Interstitial } \\
\text { Fibrosis }\end{array}$ \\
\hline $\begin{array}{ll}T & 1 \\
T & 2 \\
T & 3 \\
T & 4 \\
T & 5 \\
T & 6 \\
T & 7 \\
T & 8 \\
T & 9 \\
T & 10 \\
T & 11\end{array}$ & $\begin{array}{l}12 \\
22 \\
29 \\
33 \\
33 \\
34 \\
35 \\
41 \\
47 \\
56 \\
61\end{array}$ & $\begin{array}{l}0 \\
0 \\
0 \\
+ \\
+ \\
+ \\
+ \\
+ \\
+ \\
+ \\
+\end{array}$ & $\begin{array}{l}+ \\
+ \\
+ \\
+ \\
+ \\
+ \\
+ \\
+ \\
+ \\
+ \\
+\end{array}$ & $\begin{array}{l}0 \\
+ \\
+ \\
+ \\
+ \\
+ \\
+ \\
+ \\
+ \\
+ \\
+\end{array}$ & $\begin{array}{l}0 \\
0 \\
0 \\
0 \\
+ \\
+ \\
0 \\
0 \\
0 \\
0 \\
0\end{array}$ & $\begin{array}{l}\mathbf{0} \\
\mathbf{0} \\
\mathbf{0} \\
\mathbf{0} \\
+ \\
+ \\
+ \\
+ \\
+ \\
\mathbf{0} \\
\mathbf{0} \\
\mathbf{0}\end{array}$ & $\begin{array}{l}0 \\
0 \\
+ \\
+ \\
+ \\
+ \\
+ \\
+ \\
+ \\
+ \\
+\end{array}$ & $\begin{array}{l}0 \\
+ \\
+ \\
0 \\
+ \\
+ \\
+ \\
+ \\
0 \\
+ \\
0\end{array}$ & $\begin{array}{l}\mathbf{0} \\
\mathbf{0} \\
\mathbf{0} \\
\mathbf{0} \\
\mathbf{0} \\
\mathbf{0} \\
+ \\
\mathbf{0} \\
\mathbf{0} \\
\mathbf{0} \\
+\end{array}$ \\
\hline
\end{tabular}


LIGHT MICROSCOPY The vascular and parenchymal lesions which were observed in the lungs of the rats fed on Crotalaria spectabilis seeds are summarized in the Table.

All but three of the 11 test rats showed histological evidence of hypertensive pulmonary vascular disease in the form of medial hypertrophy of 'muscular pulmonary arteries' and the development of a muscular media in 'pulmonary arterioles'.

We define the muscular pulmonary artery in a rat to be an arterial vessel with an external diameter lying between $20 \mu$ and $400 \mu$. It has a media of circularly orientated smooth muscle fibres which does not exceed $7 \%$ of this external diameter; the media is bounded by internal and external elastic laminae. The pulmonary arteriole in a rat is an arterial vessel of less than $20 \mu$ in diameter whose wall is normally devoid of smooth muscle and consists of a single elastic lamina lined by endothelium. None of the rats showed pulmonary arteritis. The three animals in which there were no signs of hypertensive pulmonary vascular disease were killed early on in the experiment on the 12th, 22nd, and 29th days.

The same exudative and proliferative lesions occurred in the lungs of the test rats as previously described by Kay et al. (1967a). The changes were more severe in the test animals killed after the 30th day of the experiment, thus the increase in severity of the exudative changes in the lungs apparently coincided with the elevation of pulmonary arterial pressure as deduced by an increase in right ventricular weight. The exudative lesions encountered in the lungs of the rats fed on Crotalaria spectabilis seeds were as follows. In four rats there was recent intra-alveolar haemorrhage: in nine animals siderophages were present in some of the alveolar walls and spaces suggegting previous haemorrhage. Dilated lymphatic vessels were seen in the interlobular and perivascular fibrous tissue in seven of the rats. In

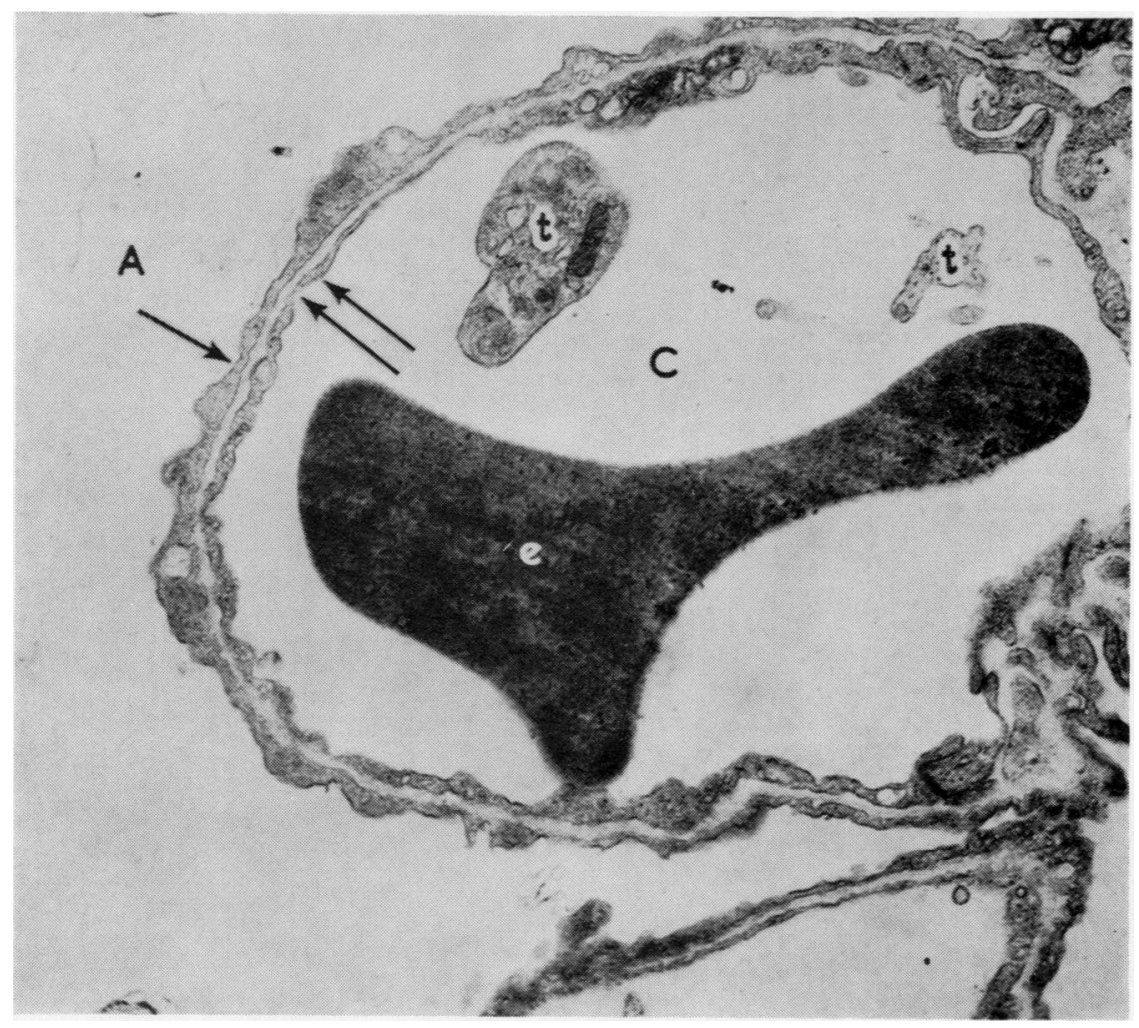

FIG. 2. Normal rat. Alveolar capillary. The lumen $(C)$ contains an erythrocyte (e) and two thrombocytes $(t)$. The alveolar space $(A)$ is lined by membranous pneumocytes (arrow) which are separated from the endothelium (2 arrows) by a thin amorphous layzr. Electron micrograph. $\times 10,000$. 
two cases some of the alveolar spaces contained eosinophilic coagulum. A mild degree of interstitial fibrosis occurred in two rats. A proliferation of mast cells was observed in all but one of the test rats: the exception was the first animal to be killed on the 12th day of the experiment. In normal rats, mast cells were scanty and confined to the peribronchial, perivascular, and subpleural connective tissue. In the test rats, mast cells had extended to occupy the connective tissue of the alveolar septa.

In all the test and control rats, cells were seen either lying free in the alveolar spaces or projecting from their attachment to the alveolar walls. In the test rats, however, the number and size of these alveolar cells was greatly increased. Thus, whereas in control rats their diameter did not exceed $11 \mu$, in the rats fed on Crotalaria spectabilis seeds they frequently attained a diameter of $25 \mu$.

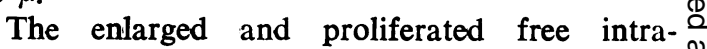
alveolar cells tended to remain separate or form is aggregates consisting of three or four cells. Those $\vec{\circ}$ which were attached to the wall sometimes formed a continuous layer reminiscent of a columnar $\vec{\omega}$ epithelium. Their cytoplasm was slightly eosino- $\rightleftharpoons$ philic and finely granular and was often highly $\vec{x}$ vacuolated, giving it a 'foamy' appearance. The $\underset{\perp}{\sim}$ nuclei were large and rounded, often with one or $i$ sometimes two prominent dark nucleoli. Some of $\mathcal{G}$ these cells contained brown pigment which did $\overrightarrow{0}$ not give a positive staining reaction with potas- $工$ sium ferrocyanide, indicating that the cells were $\vec{c}$ not siderophages.

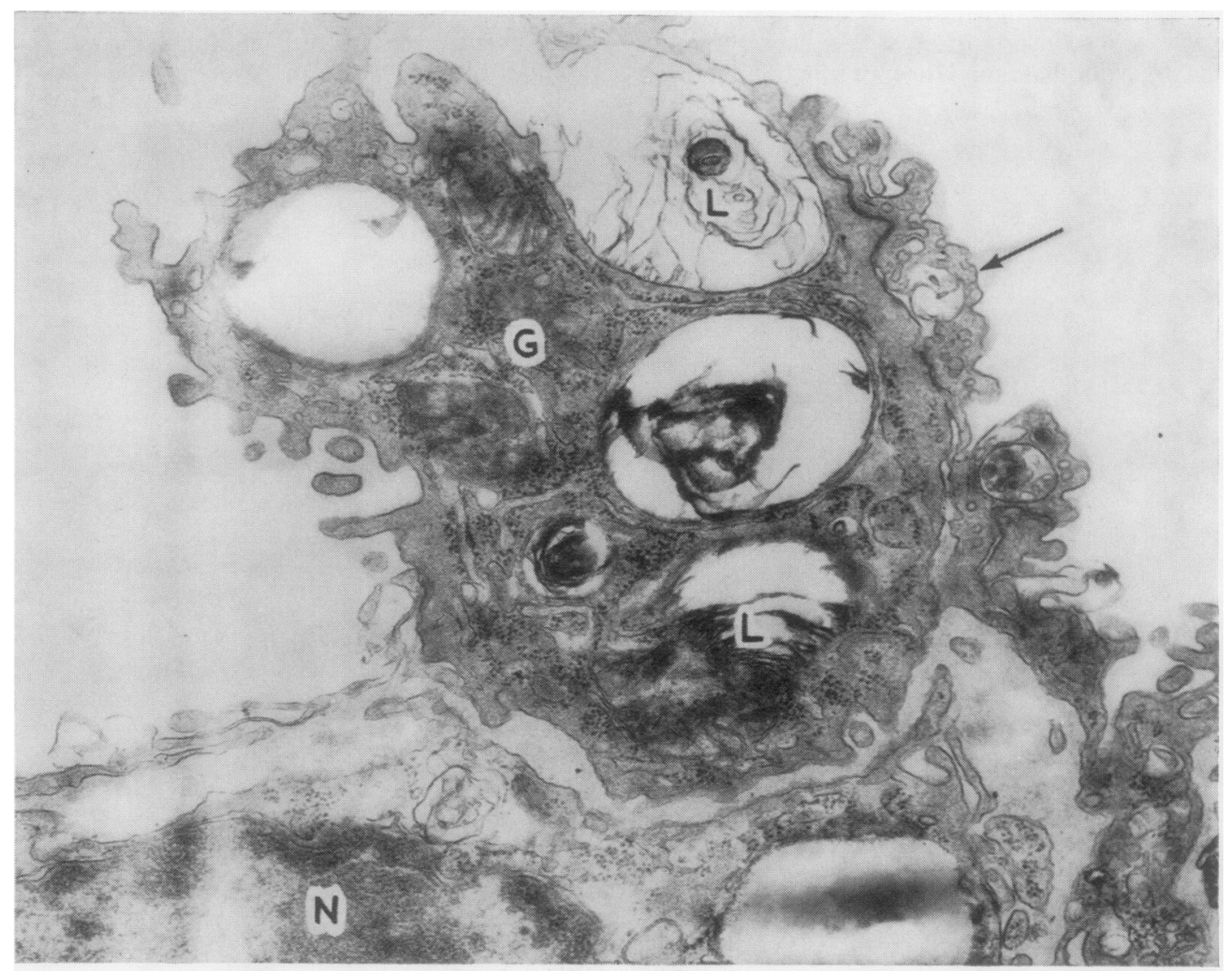

FIG. 3. Normal rat. Granular pneumocyte $(G)$ attached to alveolar wall. Note the irregular, short microvilli and intracytoplasmic lamellar secretory inclusions $(L)$. One side of the granular pneumocyte is invested by a membranous pneumocyte (arrow). The subjacent alveolar septum contains parts of the nucleus $(N)$ and cytoplasm of an interstitial cell. Electron micrograph. $\times 25,000$. 


\section{ELECTRON MICROSCOPY}

CONTROL RATS The ultrastructure of the normal alveolar wall was studied in five of the nine control rats. The alveolar spaces were lined by two types of epithelial cells as described by Low (1953) and Schulz (1959). Most of these were of the variety called type 1 or membranous pneumocytes. The nuclei of these cells were generally accommodated in the corners and angles of the alveoli, with scanty, small mitochondria and a little endoplasmic reticulum situated round about them, leaving wide areas of the alveolar wall covered by a thin, flat, and often featureless film of cytoplasm (Fig. 2). Interspersed between the membranous pneumocytes were the much larger type 2 or granular pneumocytes. These cells, which were usually situated at the recesses of alveoli, shared the same basal lamina as the membranous pneumocytes and were joined to them by junc- tional complexes. Occasionally they were partially invested by a thin cytoplasmic extension from an adjoining membranous pneumocyte. The granular pneumocytes possessed abundant cytoplasm containing numerous large mitochondria, a welldeveloped rough endoplasmic reticulum, and prominent lamellated or spiral osmiophilic secretory inclusions which are usually called lamellar bodies (Fig. 3). The cell surface was thrown up into characteristic irregular short microvilli. Solitary granular pneumocytes were also seen lying free within the alveolar lumen (Fig. 4). The interstitial tissue of the alveolar wall consisted of collagen fibres and elastic tissue together with occasional interstitial cells resembling fibroblasts or macrophages. No mast cells were seen. The alveolar capillaries were lined by a thin sheet of endothelial cytoplasm showing occasional flaskshaped surface indentations (caveolae) and containing occasional small vacuoles: the presence of

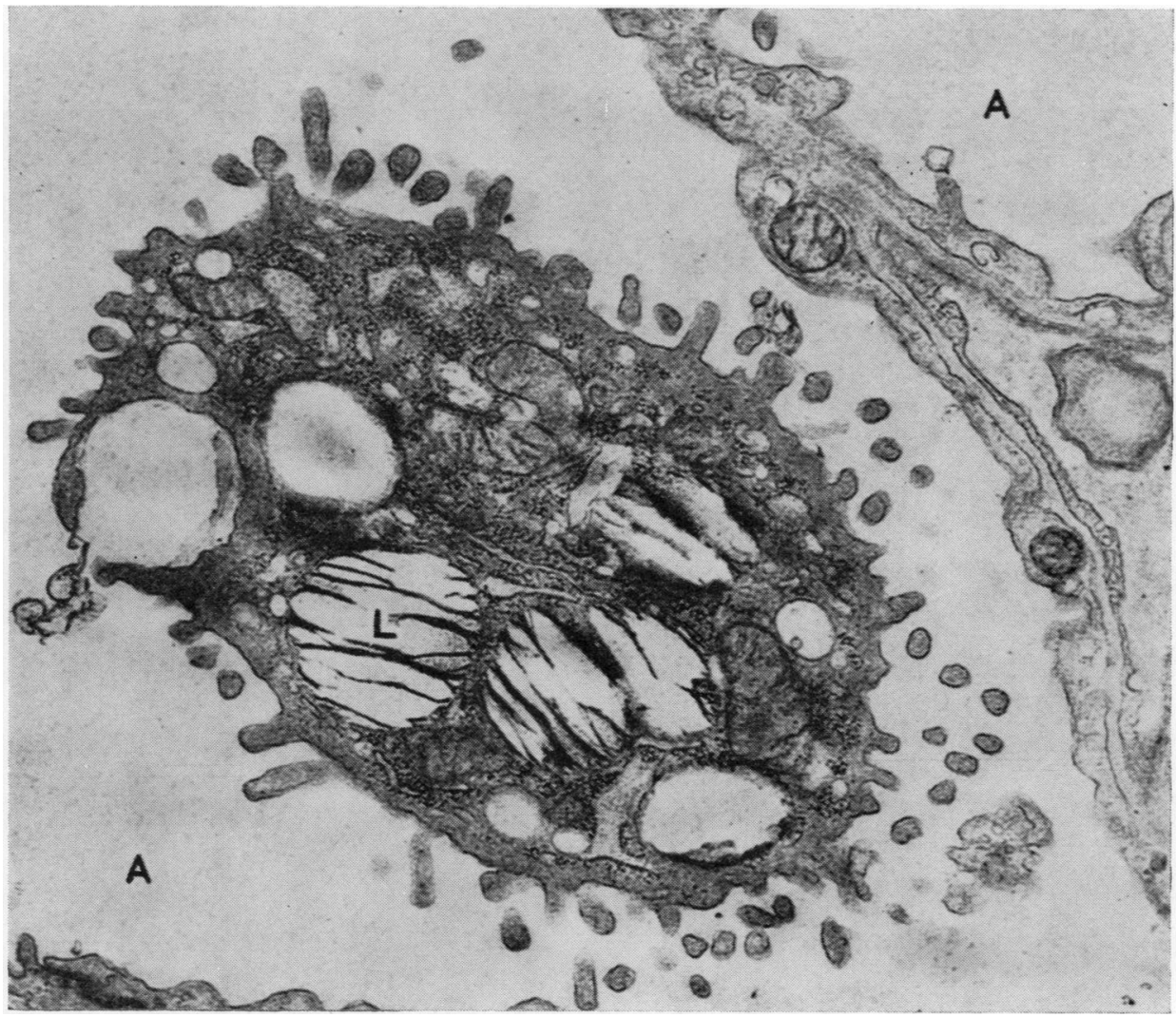

FIG. 4. Normal rat. Granular pneumocyte lying free in alveolar lumen (A). Note intracytoplasmic lamellar bodies $(L)$ and irregular, short microvilli. Electron micrograph. $\times 15,000$. 


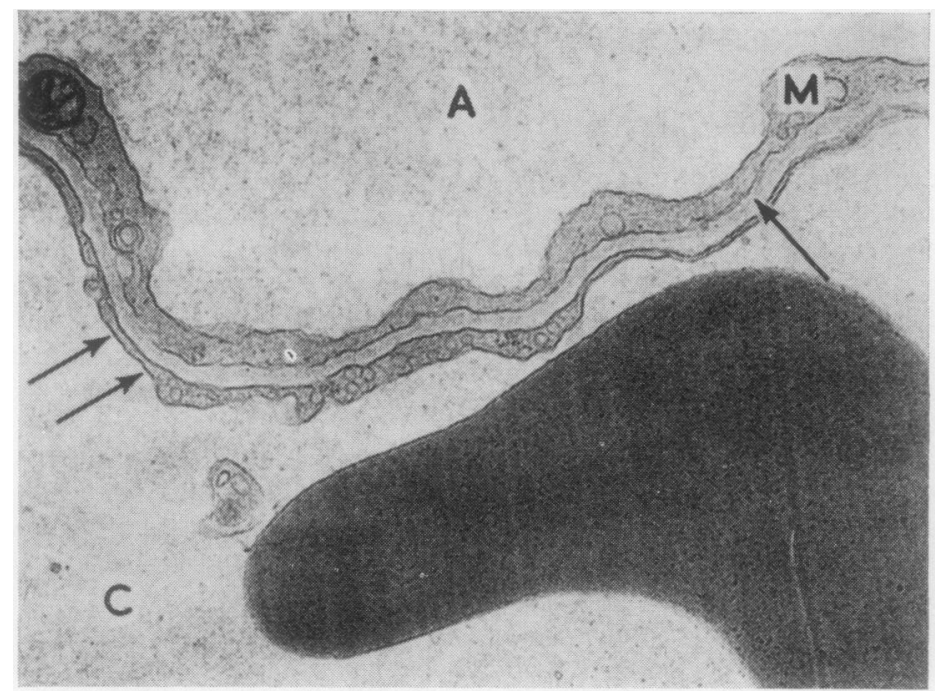

FIG. 5. Normal rat. Alveolar-capillary wall. The capillary $(C)$ contains an erythrocyte and is lined by a thin sheet of endothelial cytoplasm ( 2 arrows). The alveolus $(A)$ is lined by a membranous pneumocyte $(M)$. The epithelial and endothelial cells are separated by an amorphous layer (arrow) composed of their fused basal laminae. Electron micrograph. $\times 18,750$.

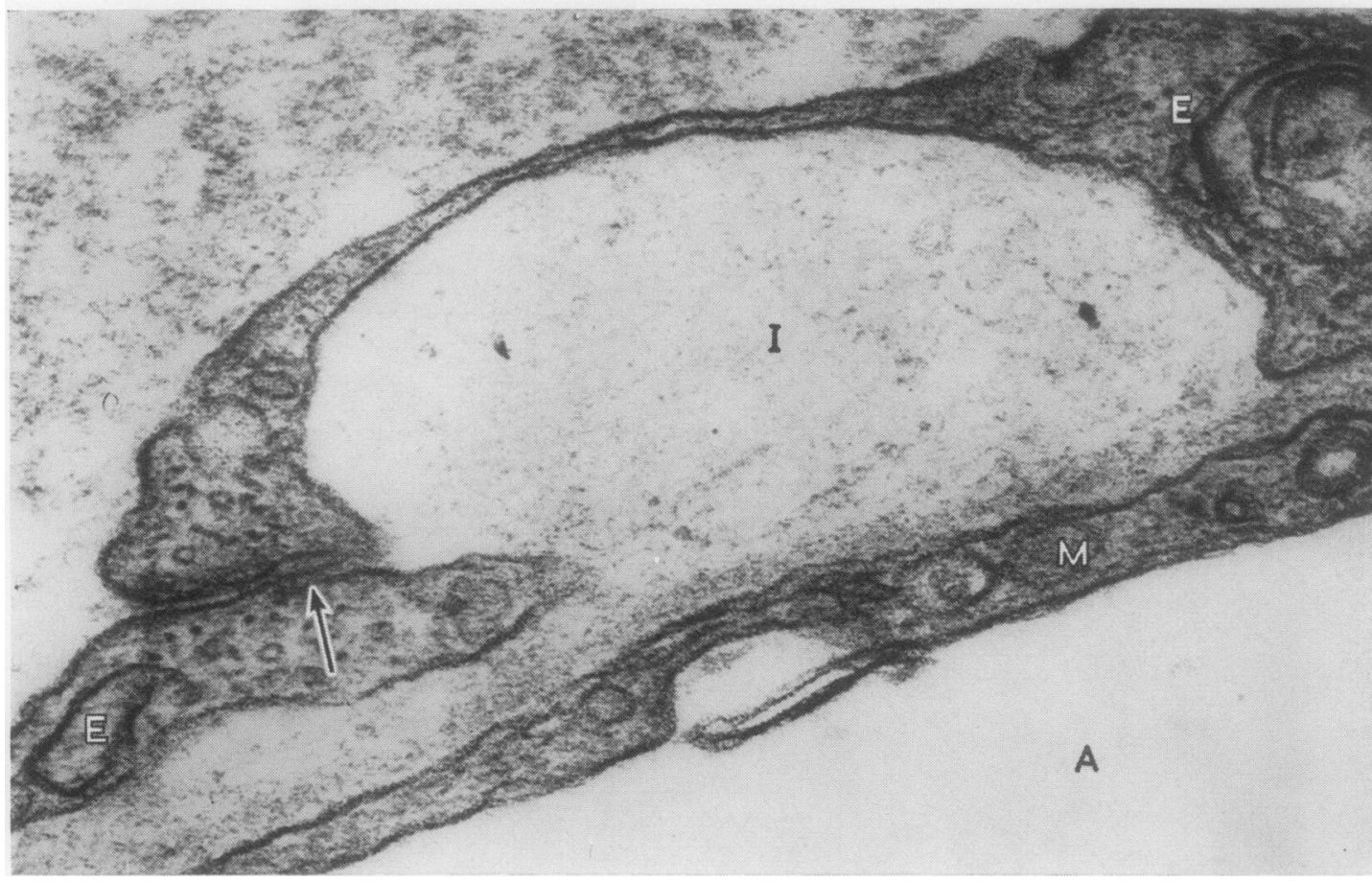

FIG. 6. Test rat. Alveolar-capillary wall. Focal increase in width of interstitial space $(I)$ separating capillary endo thelial cell $(E)$ from membranous pneumocyte $(M)$ lining alveolar space $(A)$. Arrow indicates junction between two
endothelicl cells. Electron micrograph. $\times 73,600$. 
these caveolae and vacuoles is suggestive of the uptake and transport of fluid across the cell (micropinocytosis). This film of cytoplasm was less than $50 \mathrm{~m} \mu$ thick in some places, except where there was bulging of the wall due to incorporation of the nucleus. The membranous pneumocytes were often so closely applied to the capillary wall that no true interstitial space existed between them. In these areas the epithelial and endothelial cells were separated by an amorphous layer, 50 to $160 \mathrm{~m} \mu$ in thickness, representing their fused basal laminae (Fig. 5).

TEST RATS Electron microscopy was carried out on the lungs of all the test rats. Ultrastructural changes in the lungs of these animals comprised alterations in the alveolar-capillary wall, proliferation of the alveolar epithelial cells, and the occurrence of mast cells in the alveolar septa.
Each of these three changes will now be considered in detail.

The alveolar-capillary wall showed irregular areas of thickening due to an increase in the width of the interstitial space lying between the membranous pneumocytes and the endothelial cells (Fig. 6). The width of this space was very variable, extending from the normal thickness of about $100 \mathrm{~m} \mu$ up to $600 \mathrm{~m} \mu$ in extreme cases. Both the endothelial cells and pneumocytes showed extensive caveolae and contained numerous micropinocytic vesicles (Fig. 7), suggesting that the widening of the interstitial space was a manifestation of interstitial oedema secondary to exudation of fluid from the capillary lumen. In some instances, so much fluid appeared to have accumulated in the interstitial space that it had swollen to produce bulbous vesicles covered by an attenuated layer of endothelial cytoplasm which projected

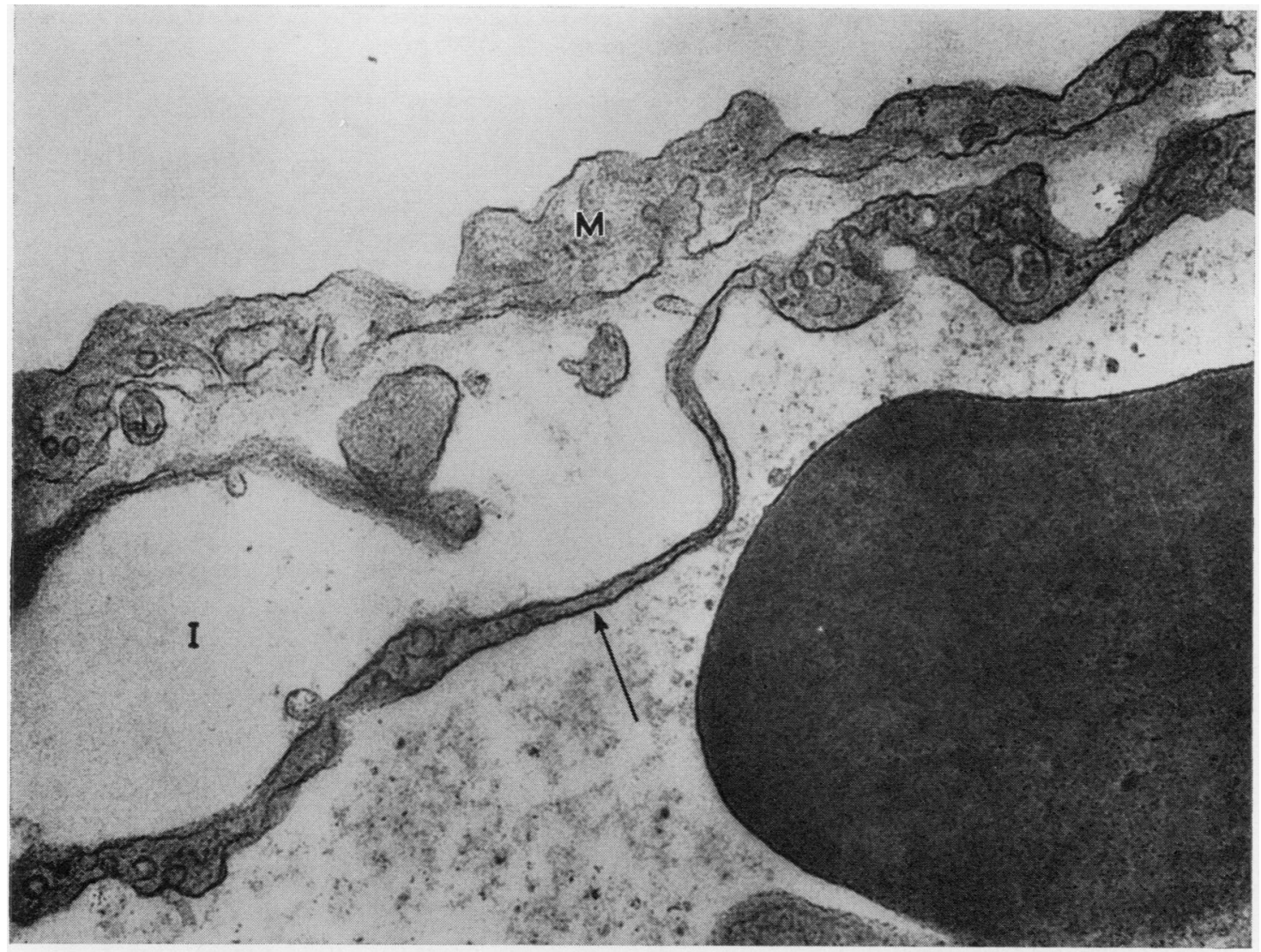

FIG. 7. Test rat. Alveolar-capillary wall. Oedematous thickening of interstitial space (I). Note caveolae and micropinocytic vacuoles in membranous pneumocyte $(M)$ and endothelial cell (arrow). Electron micrograph. $\times 46,000$. 


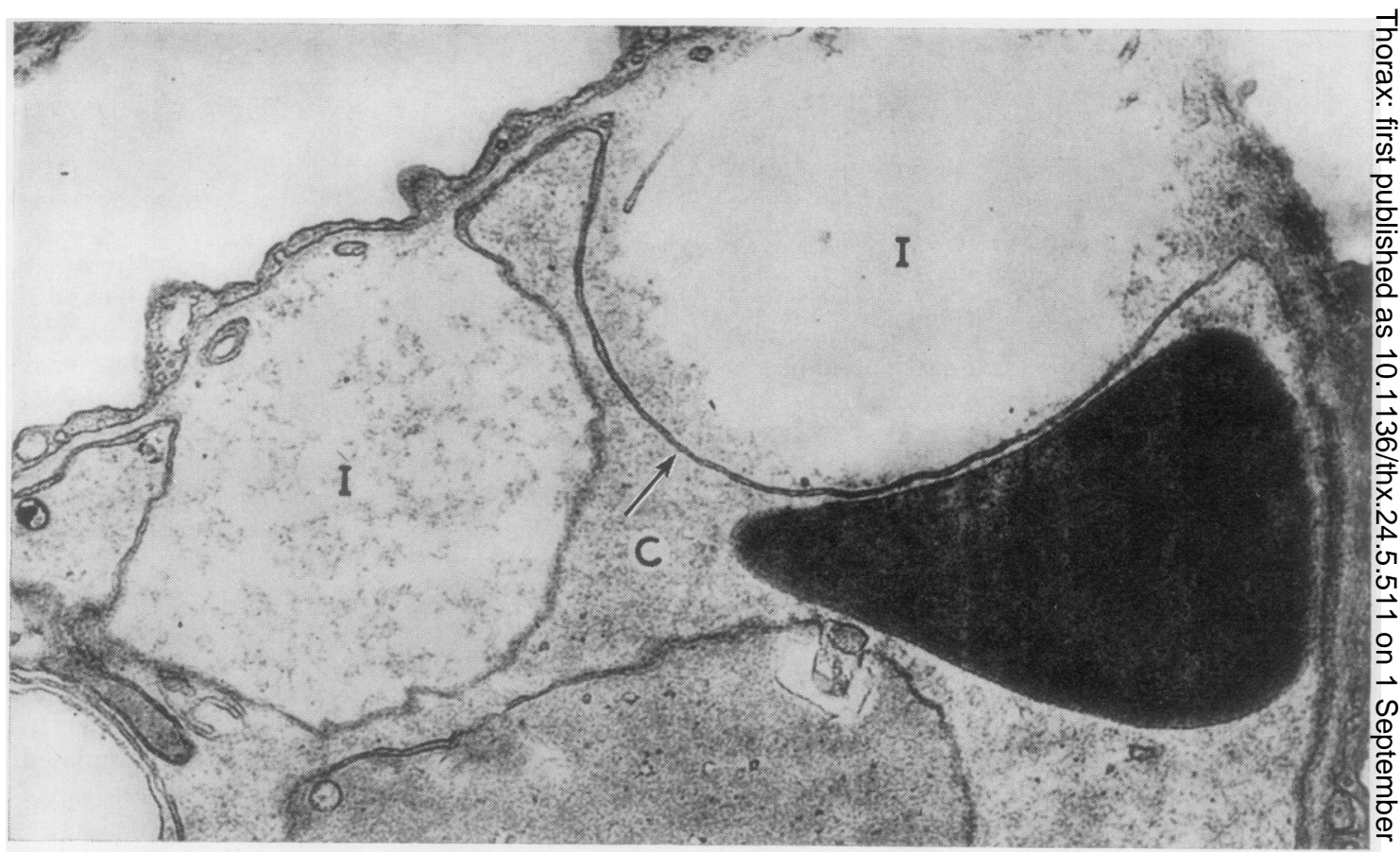

FIG. 8. Test rat. Two oedematous 'endothelial vesicles' $(I)$ covered by a thin layer of endothelial cytoplasm (arrow) $\vec{\oplus}$ project into lumen $(C)$ of alveolar capillary. Electron micrograph. $\quad \times 15,000$.

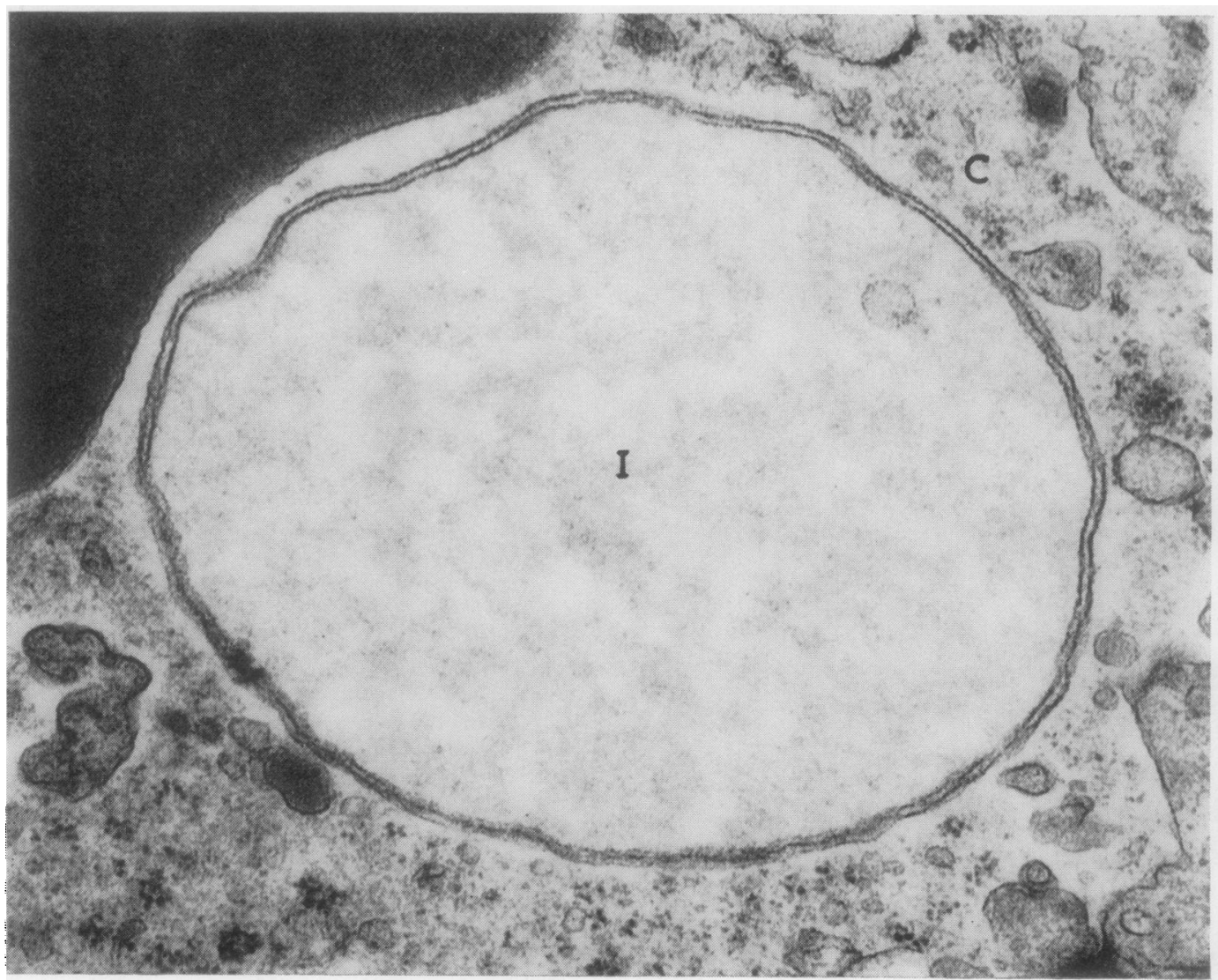

FIG. 9. Test rat. Alveolar capillary. An 'endothelial vesicle' $(I)$ sectioned distal to its point of attachment to the wall, apparently lies free within the lumen $(C)$. The wall of the vesicle consists of endothelial cytoplasm. Part of an erythrocyte is shown at top left corner of picture. Electron micrograph. $\quad \times 37,500$. 
into the capillary lumen (Fig. 8). Occasionally, similar thin-walled oedematous 'endothelial vesicles' were found apparently free within the capillary lumen (Fig. 9). These were very large, often with a diameter exceeding $2.5 \mu$, and had clearly been sectioned distal to their point of attachment to the capillary wall (Fig. 10).

The proliferated alveolar epithelial cells were identified as granular pneumocytes. These cells differed from their counterparts in the control rats because they were greatly enlarged and their cytoplasm contained larger secretory inclusions composed of thicker and denser lamellae (Fig. 11). Their cytoplasm was also vacuolated and contained larger mitochondria. The nuclei were proportionately enlarged and the cell surface showed the normal complement of microvilli. Many of the enlarged granular pneumocytes had desquamated into the alveolar spaces. Myelin figures and lattice structures composed of electron-dense osmiophilic membranes were seen in the alveolar spaces, usually in close proximity to granular pneumocytes (Fig. 12). The alveolar spaces also contained occasional macrophages which were easily distinguished from granular pneumocytes by their lack of lamellar bodies, by their smaller mitochondria, by their larger microvilli, and by their abundant cytoplasmic vacuoles and lipid droplets (Fig. 13).

Mast cells were identified in the connective tissue of the alveolar septa. These cells possessed scattered microvilli and their cytoplasm was

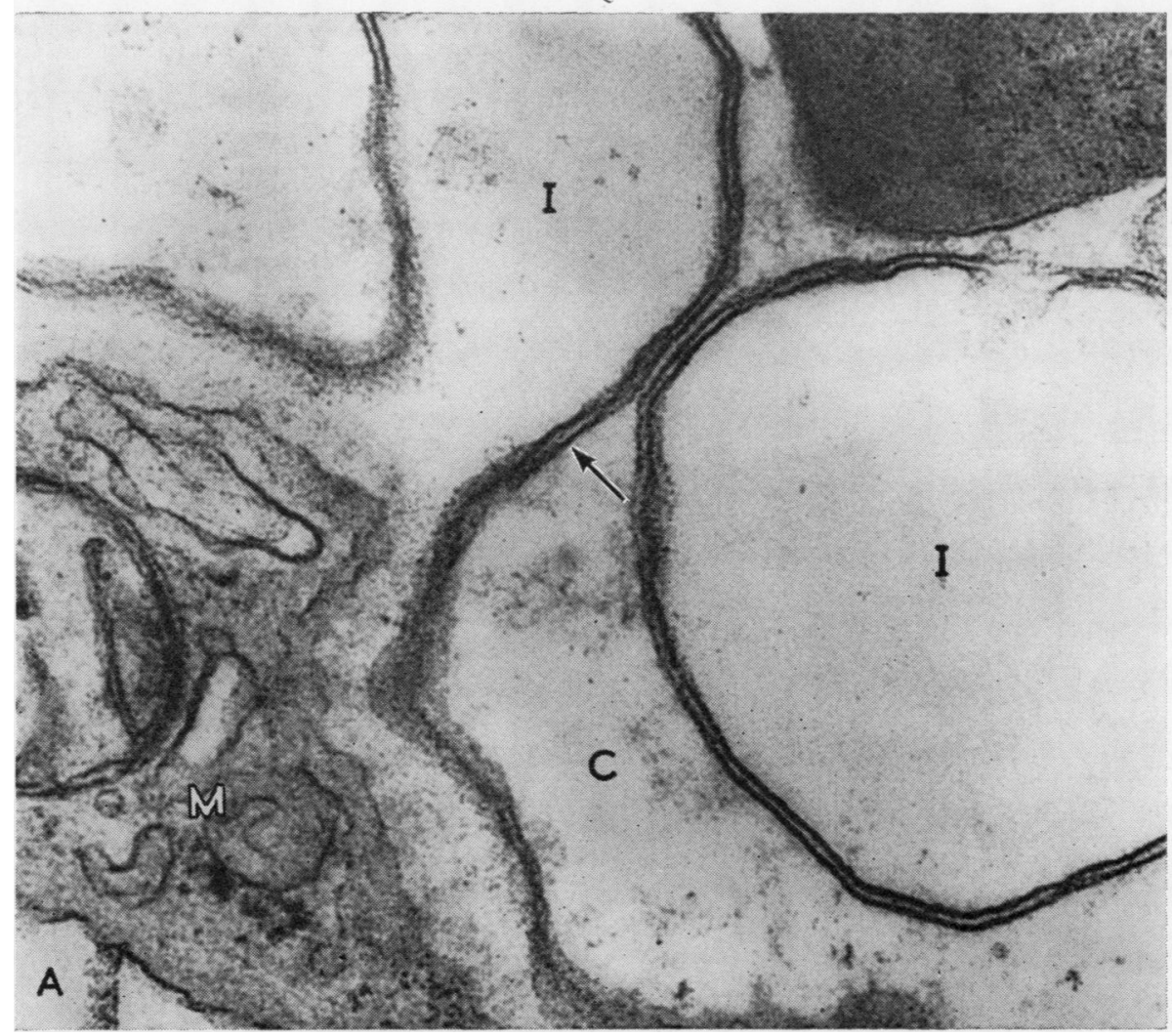

FIG. 10. Test rat. Alveolar-capillary wall. Two 'endothelial vesicles' (I) project into capillary lumen $(C)$. These are formed by accumulation of fluid in interstitial space separating alveolar epithelial cell $(M)$ from endothelial cell (arrow). Vesicle on right has been sectioned distal to its point of attachment to wall, and apparently lies free in lumen. Erythrocyte at top right of picture. Alveolar space (A) at bottom left. Electron micrograph. $\times 75,000$. 


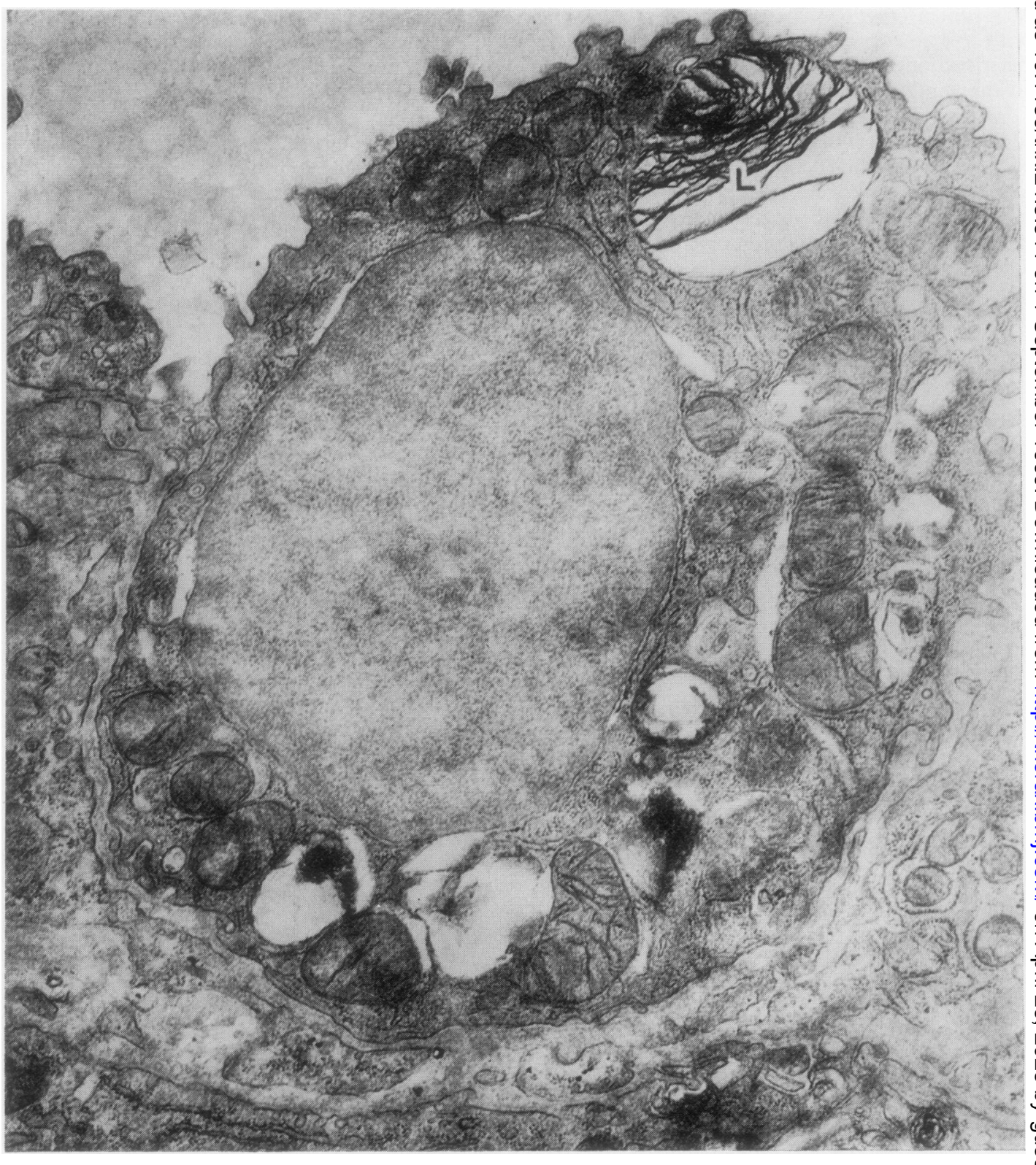

FIG. 11. Test rat. Enlarged granular pneumocyte attached to alveolar wall. Note large lamellar body (L) ana' prominent mitochondria. Electron micrograph. $\times 18,750$. 


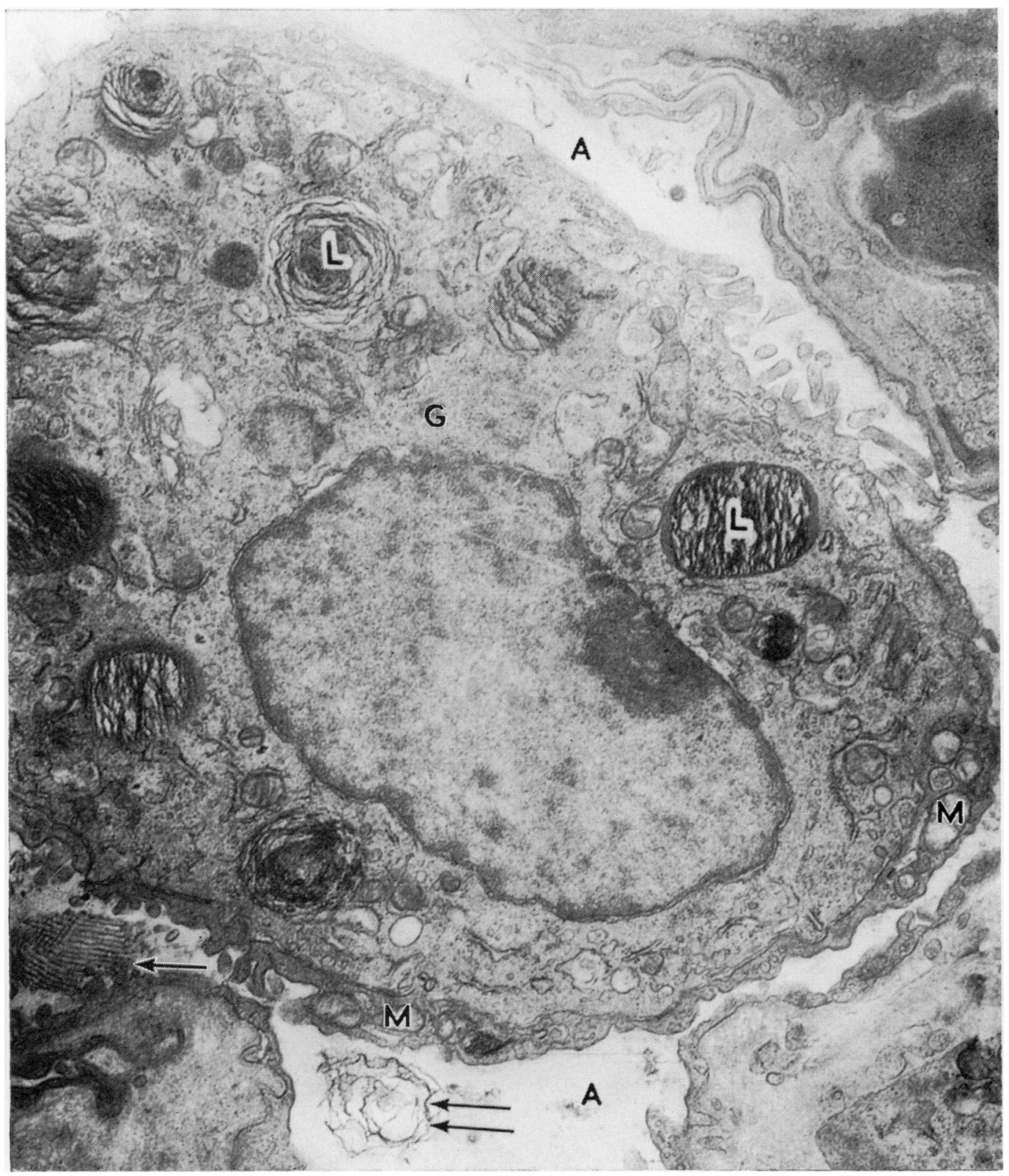

FIG. 12. Test rat. A large granular pneumocyte $(G)$ is partly covered by thin membranous pneumocytes $(M)$. Note lamellar bodies $(L)$ in granular pneumocyte. Alveolar space $(A)$ contains phospholipid lattice (arrow) and myelin figure ( 2 arrows). Electron micrograph. $\times 12,500$. 
FIG. 13. Test rat. Alveolar macrophage. Note the prominent microvilli, lipid droplets (arrows), and vacuoles $\mathcal{O}_{<}$ (V). Electron micrograph. $\times 18,750$. 


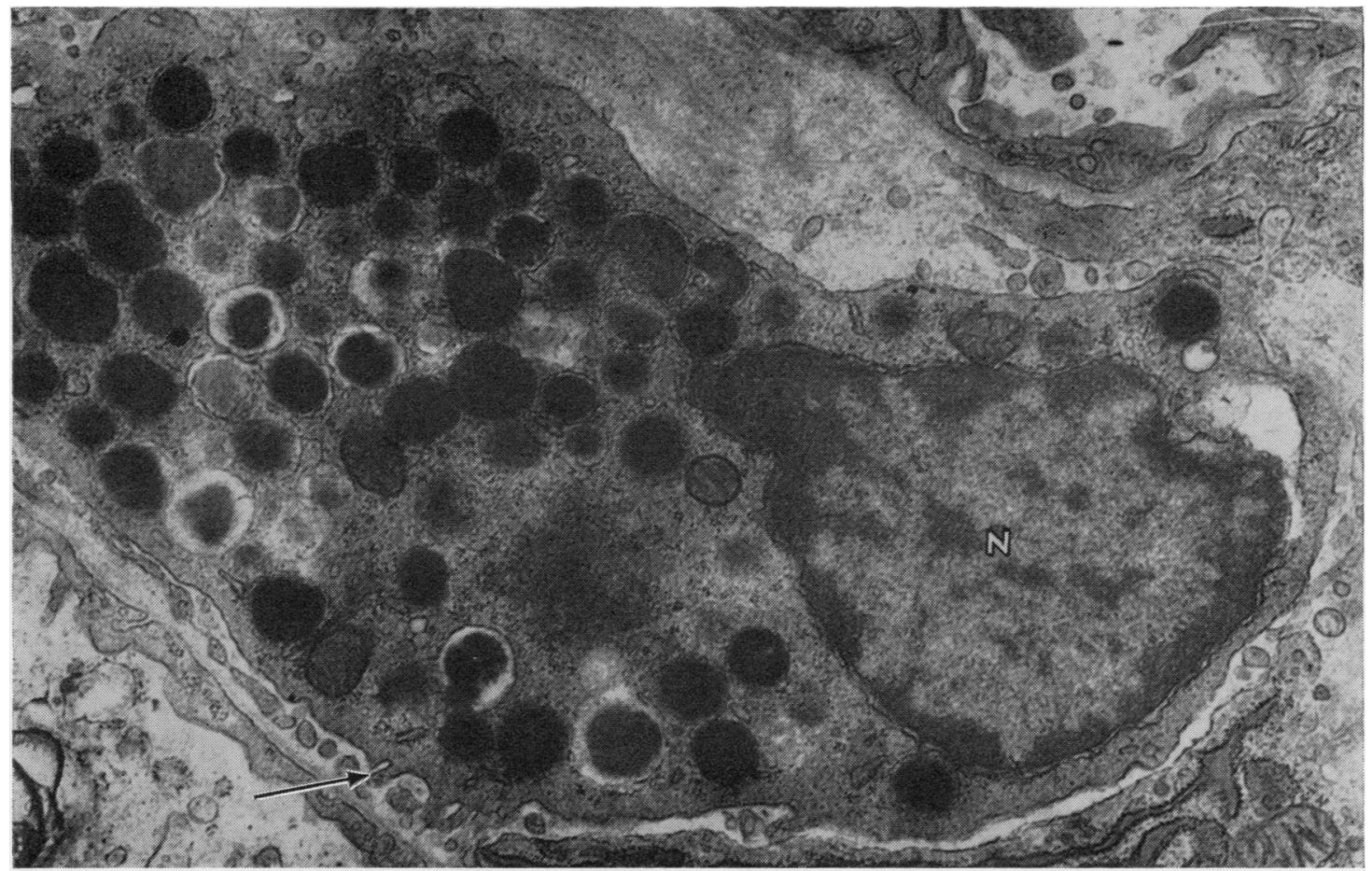

FIG. 14. Test rat. Mast cell in alveolar wall. The cell contains a nucleus $(N)$ and is packed with numerous dense osmiophilic granules. Note the occasional microvilli (arrow). Electron micrograph. $\times 16,600$.

packed with dense osmiophilic homogeneous granules reducing the intergranular cytoplasm to fragmentary rough endoplasmic reticulum, scattered ribosomes, and an occasional mitochondrion (Fig. 14).

\section{DISCUSSION}

ALVEOLAR-CAPILLARY WALL The triad of lesions comprising widening of the interstitial space between the capillary endothelium and alveolar epithelium, the development of intra-luminal endothelial vesicles, and the increased micropinocytic activity of endothelial and epithelial cells appears to represent the early ultrastructural phase of pulmonary oedema. A similar combination of fine structural changes was described by Schulz (1959), who studied the development of pulmonary oedema in rats following an intraperitoneal injection of $\alpha$-naphthylthiourea. In the early stages he observed swelling of the capillary basement membrane, intraluminal endothelial vesicles, and vacuolation of the endothelial and epithelial cells. Later, there was disintegration of the membrane system of the capillary wall, and oedema fluid accumulated in the alveolar spaces. Valdivia and his colleagues (Valdivia, Sonnad, Hayashi, and Lalich, 1967b ; Valdivia, Lalich, Hayashi, and Sonnad, 1967a) studied the ultrastructural changes in the alveolar wall of young male Sprague-Dawley rats given a single subcutaneous injection of the alkaloid monocrotaline, the active constituent of Crotalaria spectabilis. They observed vesiculation of capillary endothelial cells, interstitial oedema, and oedematous swelling of the alveolar epithelium. Some of the animals were also given an intravenous dose of Thorotrast immediately before death. These animals showed leakage of electron-dense Thorotrast granules from the capillary lumens into the endothelial vesicles and interstitial space.

Pulmonary oedema is caused by the interaction of various factors which are in a complex relationship to one another. The amount of fluid filtered through the pulmonary capillary wall is determined by the intraluminal blood pressure, the capillary permeability, by the osmotic pressure exerted by the plasma proteins, and by the inter- 
stitial fluid pressure. Since there is no evidence that primary alterations in the plasma proteins and pulmonary tissue fluid pressure occur in rats poisoned with Crotalaria spectabilis, it follows that the pulmonary oedema must be due either to a change in the capillary permeability or to an increase in the capillary intraluminal blood pressure, which may in turn be secondary to constriction or obstruction of the small pulmonary veins. The purely morphological observations presented in this paper do not permit us to determine which of these two factors is operative, although earlier work has suggested that Crotalaria spectabilis intoxication may be accompanied by enlargement of the intimal fibromuscular pads which are a normal anatomical feature of the small pulmonary veins of the rat (Kay and Heath, 1966). Constriction of this muscle might impede pulmonary venous blood flow and give rise to a secondary increase in the capillary blood pressure, leading to the development of pulmonary oedema.

ALVEOLAR CELl PROLIFERATION The proliferated cells which lined the alveolar walls and occupied the alveolar spaces of rats given Crotalaria spectabilis had the ultrastructural characteristics of granular pneumocytes. Prior to use of the electron microscope, these cells were considered to be either proliferated bronchiolar epithelial cells or macrophages according to whether they were attached to the alveolar wall or lay free within the alveolar spaces (Kay, Gillund, and Heath, 1967a). Electron microscopy enables the various types of alveolar cell to be distinguished with ease. Granular pneumocytes are characterized by the possession of a microvillous cytoplasmic border and intracytoplasmic lamellated secretory inclusions. These lamellar bodies were originally thought to be derived from mitochondria because of their superficial morphological resemblance to these structures (Schulz, 1959). It has been shown, however, that the lamellar bodies exhibit a peripheral rim of acid phosphatase activity and that they are therefore probably lysosomal in origin (Balis and Conen, 1964 ; Kikkawa, Motoyama, and Gluck, 1968 ; Kuhn, 1968). There is now considerable evidence to indicate that the lamellar bodies of granular pneumocytes are directly concerned in the elaboration, storage, and release of the pulmonary surface-active material: this subject is well reviewed by Conen and Balis (1969). The routine procedures used for fixing and staining lung for electron microscopy destroy the surfactant layer which should, on the basis of physiological and chemical evidence, be seen to line the alveoli. Recently, Weibel and Gil (1968 have been able to demonstrate such a lining filr? by perfusing rat lungs with glutaraldehyde throug the vascular bed, which fixed the surfactant in situ. Electron micrographs showed that the alveolar epithelium was covered by a thin extracellular lining layer which was independent of the external plasma membrane of the epithelial cells It was composed of two phases: a lamellar super? ficial layer of phospholipid, and a basal laye probably containing proteins.

The proliferation and enlargement of granulaigr pneumocytes which occurred in the rats fed of Crotalaria spectabilis suggest that there may have been some alteration in the production or nature of the pulmonary surfactant, but the reasons for this are obscure. We noted that excessive numbers of myelin figures and lattices were seen in the alveolar spaces of test rats: these structures closely resemble the artificial phospholipid mem branes prepared by Lucy and Glauert (1964) and are probably related to the pulmonary surfactanto Proliferation of granular pneumocytes occurs iff several diseases: electron microscopy has estabo lished that the proliferated alveolar cells whic characterize pulmonary alveolar proteinosis (Rosen, Castleman, and Liebow, 1958) and de⿳⺈ squamative interstitial pneumonia (Liebow, Steek and Billingsley, 1965) are in fact granular pneumo $\overrightarrow{-7}$ cytes (Liebow, 1968 ; Brewer, Heath, and Asquith 1969). It seems likely that the alveolar cells which proliferate in the early cellular phase of diffuse fibrosing alveolitis are also granular pneumocyte (Scadding and Hinson, 1967). We have observe a proliferation of granular pneumocytes in patient suffering from 'busulphan lung' (Heard and Cooke, 1968), and in dogs suffering from. radiation-induced pulmonary damage. Thes 8 findings endorse the contention of Spencer (1962 that alveolar cell hyperplasia is merely a non specific reaction to chronic pulmonary injury.

HYPERTENSIVE PULMONARY VASCULAR DISEASE Th' mechanism by which ingestion of Crotalarif spectabilis seeds induces pulmonary hypertensio is not clear. Valdivia and his colleagues (Valdiviä et al., 1967a) believe that the pulmonary capillar lesions themselves are sufficiently severe to cause medial hypertrophy of pulmonary arteries and right ventricular hypertrophy. However, we do not think that the interstitial oedema of the alveolarD capillary walls and the formation of endothelias vesicles would cause a significant increase in puf monary vascular resistance. The alveolar-capillar $\$$ lesions are, in our view, more likely to represen 
the effects of an increased capillary blood pressure rather than to be its cause.

It could be argued that the thickening of the blood-air barrier consequent upon oedema of the capillary wall might induce a state of chronic hypoxia, which in turn would cause constriction of pulmonary arteries, and so lead to the development of pulmonary arterial hypertension. This postulated sequence of events is unlikely to be the cause of Crotalaria pulmonary hypertension because the histological type of hypertensive pulmonary vascular disease encountered in Crotalaria spectabilis intoxication is quite different from that which occurs in hypoxic pulmonary hypertension in man (Hasleton, Heath, and Brewer, 1968) and animals (Alexander, Will, and Wolff, 1965; Abbott, Barer, Clegg, and Shaw, 1968 ; James and Thomas, 1968). Hypoxic pulmonary hypertension is characterized by muscularization of pulmonary arterioles, a lack of medial hypertrophy in muscular pulmonary arteries, and the development of longitudinal muscle in the intima of pulmonary arterioles and arteries. In Crotalaria pulmonary hypertension, however, there is pronounced medial hypertrophy of muscular pulmonary arteries, and in some cases, an acute necrotizing arteritis: we have not seen longitudinal muscle in the intima of pulmonary arterioles and arteries in this condition.

A proliferation of mast cells occurs in the lungs of a proportion of rats given Crotalaria spectabilis seeds (Takeoka, Angevine, and Lalich, 1962 ; Kay et al., 1967a). Rat mast cells are rich in 5-hydroxytryptamine (Benditt, Wong, Arase, and Roeper, 1955), which is known to constrict small pulmonary blood vessels in some animals (Aviado, 1965). In view of these observations, it was tempting to postulate that ingested monocrotaline might stimulate the proliferation of pulmonary mast cells and that release of 5-hydroxytryptamine from them might lead to constriction of small pulmonary blood vessels, with the eventual development of pulmonary hypertension. This hypothesis was especially attractive, since it would account for the latent period which is known to elapse between the administration of monocrotaline and the development of pulmonary hypertension (Kay et al., 1967.b). It has, however, been shown that the multiplication of lung mast cells, which occurs in these circumstances, appears to be a secondary phenomenon related to the development of exudative lesions in the lung parenchyma, and that mast cells are not concerned in the genesis of the pulmonary hypertension (Kay et al., 1967a). Moreover, a study of the concentration of 5-hydroxytryptamine in the platelets, plasma, and lungs of rats fed on Crotalaria spectabilis seeds has shown no evidence that ingested monocrotaline interferes with the metabolism and transport of this amine (Kay, Crawford, and Heath, 1968).

There is evidence that the alkaloid monocrotaline is not itself a toxic substance, but that it is dehydrogenated in the liver to produce a highly reactive derivative, monocrotaline pyrrol, which may act as an alkylating agent (Mattocks, 1968). Monocrotaline pyrrol may be transported from the liver to the lungs, where it becomes bound to the tissues and produces its toxic effects. The mechanism by which oral administration of monocrotaline induces pulmonary hypertension requires further study.

The possibility that ingestion of chemicals may induce pulmonary vascular disease has recently assumed great importance, since it has been suggested that a dramatic increase in the incidence of primary pulmonary hypertension in some countries may be related to the consumption of certain drugs (Gurtner, Gertsch, Salzmann, Scherrer, Stucki, and Wyss, 1968 ; Cahal, 1969).

\section{REFERENCES}

Abbott, J., Barer, G. R., Clegg, E. J., and Shaw, J. W. (1968). Changes in the small pulmonary blood vessels of mice exposed chronically to low oxygen tensions. J. Physiol. (Lond.), 196, $118 P$.

Alexander, A. F., Will, D. H., and Wolff, W. A. (1965). Pulmonary vascular alterations during recovery from bovine high mountain disease. Amer. J. vet. Res., 26, 1042.

Aviado, D. M. (1965). The Lung Circulation, Vol. 1, p. 275. Pergamon Press, Oxford.

Balis, J. U., and Conen, P. E. (1964). The role of alveolar inclusion bodies in the developing lung. Lab. Invest., 13, 1215.

Benditt, E. P., Wong, R. L., Arase, M., and Roeper, E. (1955). 5-hydroxytryptamine in mast cells. Proc. Soc. exp. Biol. (N.Y.), $90,303$.

Brewer, D. B., Heath, D., and Asquith, P. (1969). Electron microscopy of desquamative interstitial pneumonia. J. Path., 97, 317.

Cahal, D. A. (1969). Appetite suppressants and pulmonary hypertension. Lancet, 1, 947.

Conen, P. E., and Balis, J. U. (1969). Electron microscopy in study of lung development. Ch. 3 in The Anatomy of the Developing Lung. Ed., Emery, J. Heinemann Spastics International Medical Publications, London.

Gurtner, H. P., Gertsch, M., Salzmann, C., Scherrer, M., Stucki, P., and Wyss, F. (1968). Häufen sich die primär vasculären Formen des chronischen Cor pulmonale? Schweiz. med. Wschr., 98, 1579 and 1695 .

Hasleton, P. S., Heath, D., and Brewer, D. B. (1968). Hypertensive pulmonary vascular disease in states of chronic hypoxia. J. Path. Bact., 95, 431.

Heath, D., and Kay, J. M. (1967). Medial thickness of pulmonary trunk in rats with cor pulmonale induced by ingestion of Crotalaria spectabilis seeds. Cardiovasc. Res., 1, 74.

Heard, B. E., and Cooke, R. A. (1968). Busulphan lung. Thorax, 23, 187.

James, W. R. L., and Thomas, A. J. (1968). The effect of hypoxia on the heart and pulmonary arterioles of mice. Cardiovasc. Res., 2 , 278.

Kay, J. M., Crawford, N., and Heath, D. (1968). Blood 5-hydroxytryptamine in rats with pulmonary hypertension produced by ingestion of Crotalaria spectabilis seeds. Experientia (Basel), 24, 1149.

Gillund, T. D., and Heath, D. (1967a). Mast cells in the lungs of rats fed on Crotalaria spectabilis seeds. Amer. J. Path., 51, 1031. 
- Harris, P., and Heath, D. (1967b). Pulmonary hypertension produced in rats by ingestion of Crotalaria spectabilis seeds. Thorax, 22, 176.

- and Heath, D. (1966). Observations on the pulmonary arteries and heart weight of rats fed on Crotalaria spectabilis seeds. $J$. Path. Bact., 92, 385.

Kikkawa, Y., Motoyama, E. K., and Gluck, L. (1968). Study of the lungs of fetal and newborn rabbits. Amer. J. Path., 52, 177.

Kuhn, C. (1968). Cytochemistry of pulmonary alveolar epithelial cells. Amer. J. Path., 53, 809.

Lalich, J. J., and Merkow, L. (1961). Pulmonary arteritis produced in rats by feeding Crotalaria spectabilis. Lab. Invest., 10, 744.

Liebow, A. A. (1968). New concepts and entities in pulmonary disease. Ch. 24 in The Lung, ed. Liebow, A. A., and Smith, D. E. (International Academy of Pathology Monograph.) Williams and Wilkins, Baltimore.

- Steer, A., and Billingsley, J. G. (1965). Desquamative interstitial pneumonia. Amer. J. Med., 39, 369.

Low, F. N. (1953). The pulmonary alveolar epithelium of laboratory mammals and man. Anat. Rec., 117, 241.

Lucy, J. A., and Glauert, A. M. (1964). Structure and assembly of macromolecular lipid complexes composed of globular micelles. J. molec. Biol., 8, 727.

Mattocks, A. R. (1968). Toxicity of pyrrolizidine alkaloids. Nature (Lond.), 217, 723.
Neal W. M., Rusoff, L. L., and Ahmann, C. F. (1935). The isolation and some properties of an alkaloid from Crotalaria spectabil Roth. J. Amer. chem. Soc., 57, 2560.

Rosen, S. H., Castleman, B., and Liebow, A. A. (1958). Puımonary alveolar proteinosis. New Engl. J. Med., 258, 1123.

Scadding, J. G., and Hinson, K. F. W. (1967). Diffuse fibrosing alveolitis (diffuse interstitial fibrosis of the lungs). Thorax, 22, $29 \mathrm{cs}$

Schulz, H. (1959). Die submikroskopische Anatomie und Pathologit der Lunge (The Submicroscopic Anatomy and Pathology of the Lung), pp. 86 and 62. Springer, Berlin.

Spencer, H. (1962). Pathology of the Lung, p. 658. Pergamon Prestw Oxford.

Takeoka, O., Angevine, D. M., and Lalich, J. J. (1962). Stimulatio of mast cells in rats fed various chemicals. Amer.J. Path., 40, 545x

Turner, J. H., and Lalich, J. J. (1965). Experimental cor pulmonalê in the rat. Arch. Path., 79, 409.

Validivia, E., Lalich, J. J., Hayashi, Y., and Sonnad, J. (1967a) Alterations in pulmonary alveoli after a single injection of mond crotaline. Ibid., 84, 64 .

— Sonnad, J., Hayashi, Y., and Lalich, J. J. (1967b). Experiment ad interstitial pulmonary edema. Angiology, 18, 378

Weibel, E. R., and Gil, J. (1968). Electron microscopic demonstration of an extracellular duplex lining layer of alveoli. Resn. Physiol 4,42 . 